\title{
Chromosome Constitution 47,XYY in Relation to Stature
}

\author{
Johannes Nielsen \\ The Cytogenetic Laboratory, Århus State Hospital, Risskov, Denmark
}

Received May 13, 1974

There is a well-documented connection between the number of $Y$ chromosomes and the stature in males (Jacobs et al., 1965; Court Brown, 1968; Zeuthen and Nielsen, 1973; Nielsen and Christensen, 1974).

From studies of consecutive series of 18254 newborn boys in different countries as recently surveyed by Friedrich and Nielsen (1973) the mean prevalence of boys with double $\mathrm{Y}$ was $0.12 \%$ for males with karyotype $47, \mathrm{XYY}$.

In a population study of 3840 Danish conscripts (Zeuthen and Nielsen, 1973) we found 5 XYY males, which correlates well with the expected prevalence of $0.12 \%$ found in studies of newborn boys. The prevalence was $0.49 \%$ among those with stature $181 \mathrm{~cm}+$ and $2.99 \%$ among those with stature $190 \mathrm{~cm}+$.

At the Cytogenetic Laboratory, Risskov, we have examined approximately 4000 adult males; 3 of them had stature above $200 \mathrm{~cm}$ (208, 205 and 208); 2 of those 3 had the karyotype 47,XYY. From the statistics of stature of Danish conscripts from 1920-1966 we have calculated that the expected number of males aged $20+$ with stature above $200 \mathrm{~cm}$ in Denmark should be $17 \pm 4$.

Our findings indicate that the prevalence of XYY males increases rapidly with increasing stature. We found that the prevalence increased from $0.12 \%$ in the general population to $0.49 \%$ for those with stature of $181 \mathrm{~cm}+$ to $2.99 \%$ for those with stature of $190 \mathrm{~cm}+$ and most probably above $10 \%$ for those with stature above $200 \mathrm{~cm}$.

\section{References}

Court Brown, W. M.: Males with an XYY sex chromosome complement. J. med. Genet. 5, $341-359(1968)$

Friedrich, U., Nielsen, J.: Chromosome studies in 5,049 consecutive newborn children. Clin. Genet. 4, 333-343 (1973)

Jacobs, P. A., Brunton, M., Melville, M. M., Brittain, R. P., McClermont, W. F.: Aggressive behaviour, mental sub-normality and the XYY male. Nature (Lond.) 208, 1351-1352 (1965)

Nielsen, J., Christensen, A.-L.: Thirty-five males with double X chromosome. J. Psychol. Med. 4, 28-37 (1974)

Zeuthen, E., Nielsen, J., Yde, H.: XYY males found in a general male population. Hereditas (Lund) 74, 283-290 (1973)

Dr. Johannes Nielsen

The Cytogenetic Laboratory

Århus State Hospital

Risskov, Denmark 